\title{
A reaction to silicone spray
}

A 50-year-old man underwent surveillance colonoscopy following a right hemicolectomy for a Dukes stage A tumor of the ascending colon 5 years previously. At colonoscopy, an 8-mm polyp was found in the distal sigmoid. A silicone spray was used to assist in snaring of the polyp. The patient immediately developed pain, and the rectum was noted to become erythematous. The patient settled with conservative management. Although some silicone compounds are known to irritate mucous membranes, the active ingredient in silicone spray used in endoscopy, dimethylpolysiloxane is not harmful. However, propane and butane, which are used as propellants in the spray, can cause frostbite and freeze burns. Such sprays should be used with caution in endoscopic procedures.

\section{Competing interests: None}

Endoscopy_UCTN_Code_CPL_1AJ_2AB

\section{Grimes, P. Aughwane, M. Klein}

Department of Surgery, Chase Farm Hospital, Enfield, Middlesex EN2 8JL, UK

Bibliography

DOI 10.1055/s-0029-1243985

Endoscopy 2010; 42: E128

(c) Georg Thieme Verlag KG Stuttgart · New York . ISSN 0013-726X

\section{Corresponding author}

\section{Grimes}

Department of Surgery

Chase Farm Hospital

The Ridgeway

Enfield, Middlesex EN2 8JL

UK

carisgrimes@doctors.org.uk

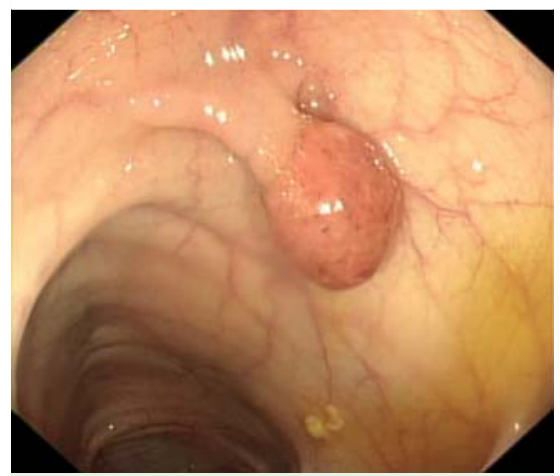

Fig. 1 Polyp in the distal sigmoid.

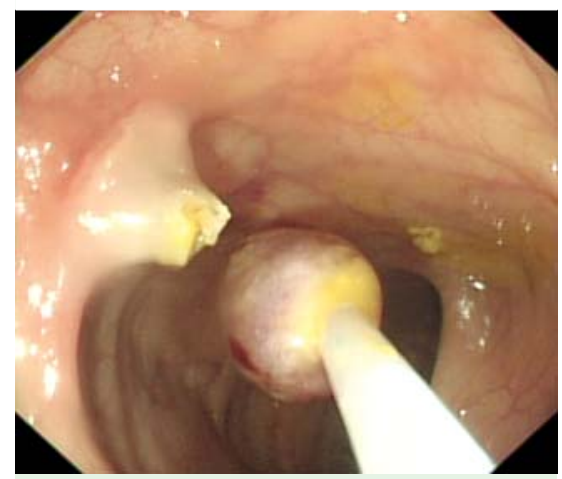

Fig. 2 Removal of polyp.
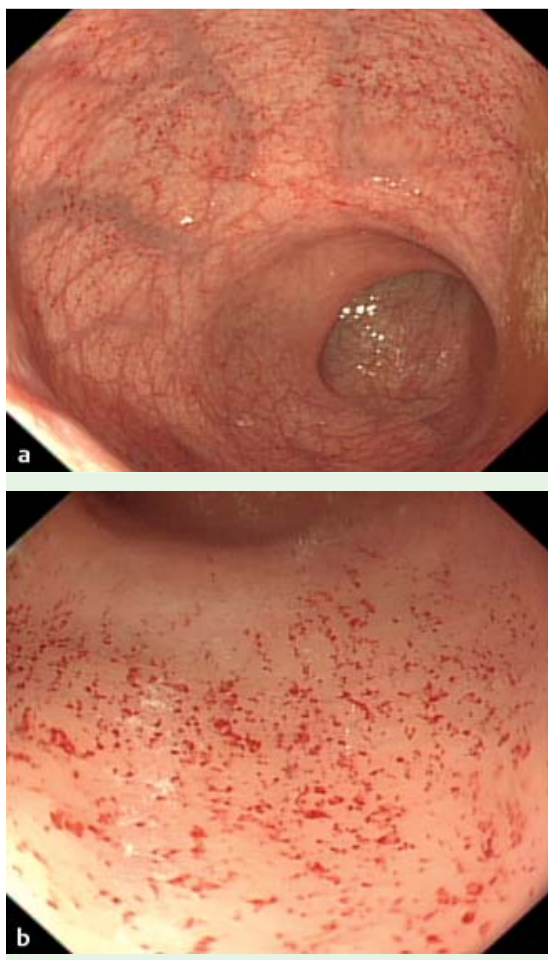

Fig. 3 a, b Erythematous reaction. 